\title{
Factors associated with visits to general practitioners in patients with schizophrenia in Malaga
}

M. C. Castillejos ${ }^{1,2^{*}}$ (D, C. Martín-Pérez ${ }^{3}$, F. Mayoral-Cleries ${ }^{4,5}$, A. Bordallo-Aragón ${ }^{4,5}$, J. Sepúlveda-Muñoz ${ }^{6}$ and

B. Moreno-Küstner ${ }^{2,5,7}$

\begin{abstract}
Background: Patients with psychiatric disorders have more physical problems than other patients, so their followup by the general practitioner is particularly important for them.

Methods: We aimed to elaborate a multilevel explanatory model of general practitioner (GP) visits made by patients with schizophrenia and related disorders (SRD). An observational, cross-sectional study was conducted from January 1, 2008 to July 1, 2011, in the area of the Clinical Management Unit of Mental Health (CMU-MH) of the Regional Hospital of Malaga (Spain). The eligible population consisted of all patients with SRD in contact with a GP residing in the study area. Our dependent variable was total number GP visits. The independent variables were: 1) patient variables (sociodemographic and clinical variables); 2) primary care centre (PCC) variables. We performed descriptive analysis, bivariate analysis and multilevel regression.

Results: Four hundred ninety four patients were included. Mean annual number of GP visits was 4.1. Female sex, living in a socioeconomically deprived area, a diagnosis of schizoaffective disorder and contact with a GP who had a more active approach to mental health issues were associated with a higher number of visits whilst being single and good communication between the PCC and mental health teams were associated with a lower number of GP visits.

Conclusions: Number of GP visits was not just associated with patient factors, but also with organisational and the involvement of health professionals, for example GPs with an active approach to mental health issues.
\end{abstract}

Keywords: Primary health care, Schizophrenia, Use of services, Medical follow-up, Physical care

\section{Background}

It has long been known that patients with severe mental disorders, such as schizophrenia or related disorders (SRD), have more physical health problems and higher mortality rates than the general population $[1,2]$. Patients with SRD have a life expectancy 13-30 years shorter than the general population [3]. SRD have been associated with an increase in morbidity and mortality [4-6].

One of the reasons why the medical situation of these patients is worse is their inadequate approach to seeking

\footnotetext{
* Correspondence: mccasang@gmail.com

${ }^{1}$ Departament of Personality, Assessment and Psychological Treatment,

University of Malaga, Campus Teatinos, Malaga, Spain

${ }^{2}$ Andalusian Group of Psychosocial Research (GAP), Malaga, Spain

Full list of author information is available at the end of the article
}

health care when they require it $[1,7]$. In addition, there is evidence that they make less use of primary care services $[4,8]$ and specialist services [9]. There is a risk that their physical co-morbidities are not detected by their GP $[2,10]$, so there is a greater risk that their physical health problems will be under-treated [11]. In some countries, such as Australia, training programs for doctors and nurses tend to minimise the importance of physical health care in mental health patients [12]. It has also been shown that patients with SRD benefit less from primary health care prevention and promotion initiatives than the general population [13, 14], despite the evidence that as a population they are more vulnerable to physical illnesses than the general population. It has been shown that regular treatment of patients with SRD

(C) The Author(s). 2018 Open Access This article is distributed under the terms of the Creative Commons Attribution 4.0 International License (http://creativecommons.org/licenses/by/4.0/), which permits unrestricted use, distribution, and 
in primary care improves survival [15]. It has also been shown that coordination between primary and specialist care is poor [16], which has a detrimental effect on the primary care of these patients.

Despite the above evidence, there have not been many studies analysing the use of primary care services by patients with SRD. The objectives of this article are to describe a multilevel explanatory model of GP visits by patients with SRD, to identify the patient factors and organisational, i.e. primary care centre (PCC) factors that are associated with number of GP visits.

\section{Methods}

This was a descriptive, cross-sectional study.

\section{Study area and temporal scope}

This study was carried out in the catchment area of the Clinical Management Unit of Mental Health (CMU-MH) of the Regional Hospital of Malaga (Spain) which has a population of 315,159 . The area has two community mental health units (CMHU): Centre and North, associated with 13 PCCs.

The information on GP visits covers the 42-month period from January 1, 2008 to July 1, 2011.

\section{Eligible population and sample}

A case register of patients with a diagnosis of SRD in the CMU-MH area of the Regional Hospital of Malaga, the Malaga Schizophrenia Case Register (RESMA), was developed to improve the care of patients with severe mental illness. Further information on the register is available in Moreno-Küstner et al. [17].

The population eligible for the study consisted of all patients on the RESMA $(N=1663)$ [18]. The sample size was calculated to be representative of the patients of each PCC. Patients were selected by simple random sampling, stratified by PCC.

The inclusion criteria were the following: a) age over 14 years old; b) clinical diagnosis of SRD according to the ICD-10; c) in contact with a PCC in the catchment area of the CMU-MH of the Regional Hospital of Malaga. The exclusion criteria were the following: a) receipt of treatment outside the study area; b) death during the observation period; c) no computerised medical history at the reference PCC.

\section{Study variables}

Our dependent variable was total number of GP visits made by patients with SRD during the three and a half-year observation period.

The independent variables were grouped into two levels: 1) patient variables; 2) PCC variables.
Patient variables were divided into sociodemographic and clinical variables (Additional file 1: Table S1). PCC variables are also shown in Additional file 1: Table S1.

\section{Data sources}

Data on total number of GP visits were obtained from digitalised primary care records (DIRAYA program). Sociodemographic and clinical information about patients was obtained from RESMA [17, 18]. Information about the PCCs was collected from their directors, who were interviewed using a questionnaire designed by the research team.

\section{Data analysis}

The categorical variables used in the descriptive analysis were frequency distribution and percentages. Descriptive statistics (mean, standard deviation, median and quantiles) were calculated for the continuous variables.

We used bivariate analysis to examine the relationships between the dependent variable (number of GP visits) and the independent variables. The means of independent, dichotomous categorical variables were compared using the Wilcoxon test. The means of other independent categorical variables were compared using the Kruskal-Wallis test. Differences were considered significant at $p<0.05$.

Finally, we constructed a multilevel, linear regression model in which level 1 was the patient, and level 2 the PCC. Beforehand we verified that there were differences between PCCs that allowed the application of the multilevel model. After all the variables were reintroduced into the model we removed non-significant variables step by step until a definitive model was obtained.

The statistical package $\mathrm{R}$ was used for the statistical analysis.

\section{Results}

We discovered that 34 of the initial sample of 528 patients $(6 \%)$ did not have a digitalised primary care history, so these patients were excluded from the study. Thirty-six of the final sample of 494 patients did not have any contact with their GP during the observation period.

The sociodemographic profile of the sample was as follows: $66.3 \%$ male; mean age 43.78 years old (standard deviation 11.64; range 19-83); $70.6 \%$ single; $64.4 \%$ had not completed secondary school; $56.9 \%$ living with their parents or friends; $42.9 \%$ unable to work; $87.1 \%$ living in an urban area and $11.5 \%$ in a socioeconomically deprived area.

Schizophrenia was the most frequent diagnosis (70\%) (Table 1). The overall severity level had been evaluated in 431 cases (87.2\%) and the majority were placed in the less severe classes (1 and 2) (Table 1). 
Table 1 The sociodemographic and clinical characteristics of patients with schizophrenia and related disorders who were in contact with general practitioner. $(N=494)$

\begin{tabular}{|c|c|}
\hline Sociodemographic characteristics & Patients N ( \\
\hline \multicolumn{2}{|l|}{ Gender } \\
\hline Male & $327(66.3 \%)$ \\
\hline Female & $167(33.8 \%)$ \\
\hline \multicolumn{2}{|l|}{ Age } \\
\hline $15-44$ & $265(53.6 \%)$ \\
\hline $45-64$ & $205(41.5 \%)$ \\
\hline$>65$ & $24(4.9 \%)$ \\
\hline \multicolumn{2}{|l|}{ Marital status } \\
\hline Single & $349(70.6 \%)$ \\
\hline Married/Civil partnership/Cohabiting & $90(18.2 \%)$ \\
\hline Separated/Divorced/Widowed & $55(11.1 \%)$ \\
\hline \multicolumn{2}{|l|}{ Educational level } \\
\hline No formal education and/or illiterate & $81(16.4 \%)$ \\
\hline Primary school & $237(48 \%)$ \\
\hline Secondary school & $126(25.5 \%)$ \\
\hline Higher education (Bachelor's degree) & $50(10.1 \%)$ \\
\hline \multicolumn{2}{|l|}{ Living arrangements } \\
\hline Alone & $54(10.9 \%)$ \\
\hline Original family/other relatives or friends & $281(56.9 \%)$ \\
\hline Own family & $102(20.6 \%)$ \\
\hline Sheltered accommodation & $52(10.5 \%)$ \\
\hline Homeless & $5(1.0 \%)$ \\
\hline \multicolumn{2}{|l|}{ Employment status } \\
\hline Employed & $76(15.4 \%)$ \\
\hline Unemployed & $85(17.2 \%)$ \\
\hline Student & $29(5.9 \%)$ \\
\hline Carer or househusband/housewife & $30(6.1 \%)$ \\
\hline Not working, receiving welfare benefits & $212(42.9 \%)$ \\
\hline Other & $62(12.6 \%)$ \\
\hline \multicolumn{2}{|l|}{ Area } \\
\hline Urban & $430(87.1 \%)$ \\
\hline Rural & $64(12.9 \%)$ \\
\hline \multicolumn{2}{|l|}{ Within a socioeconomically deprived area } \\
\hline No & $437(88.5 \%)$ \\
\hline Yes & $57(11.5 \%)$ \\
\hline \multicolumn{2}{|l|}{ Primary care centre } \\
\hline Trinidad & $50(10.1 \%)$ \\
\hline Nueva Málaga & $23(4.7 \%)$ \\
\hline Miraflores & $18(3.6 \%)$ \\
\hline Palma-Palmilla & $36(7.3 \%)$ \\
\hline Ciudad Jardín & $45(9.1 \%)$ \\
\hline Capuchinos & $32(6.5 \%)$ \\
\hline
\end{tabular}

Table 1 The sociodemographic and clinical characteristics of patients with schizophrenia and related disorders who were in contact with general practitioner. $(N=494)$ (Continued)

\begin{tabular}{ll}
\hline Sociodemographic characteristics & Patients N (\%) \\
\hline Carlinda & $17(3.4 \%)$ \\
Alameda Perchel & $33(6.7 \%)$ \\
Victoria & $40(8.1 \%)$ \\
Limonar & $37(7.5 \%)$ \\
El Palo & $69(14 \%)$ \\
Rincón de la Victoria & $56(11.3 \%)$ \\
Colmenar & $2(0.4 \%)$ \\
Out of the study area & $36(7.3)$ \\
(Missing data: 13) & \\
Community mental health centre & \\
Centre & $272(55.1 \%)$ \\
North & $222(44.9 \%)$ \\
Clinical characteristics & \\
ICD-10 Clinical diagnosis & \\
F20 Schizophrenia & $346(70 \%)$ \\
F22 Persistent delusional disorders & $53(10.7 \%)$ \\
F23 Acute and transient psychotic disorders & $46(7.3 \%)$ \\
F25 Schizoaffective disorders & $36(9.3 \%)$ \\
F21, F24, F28, F29 Schizotypal disorder, Induced & $13(2.6 \%)$ \\
delusional disorder, other non-organic psychotic \\
disorders and unspecified non-organic psychosis \\
Global level of severity & \\
Level I (low severity) & \\
Level II & \\
Level III (high severity) & \\
(Missing data:63) & \\
\hline
\end{tabular}

In $69.2 \%$ of the PCCs the mental health team visited 3 or more times per month, and in $30.8 \%$ of PCCs the team made a training visit once a month. Communication between the mental health team and GPs was rated as good or very good in $92.4 \%$ of cases, communication between GPs and primary care nurses was rated as good $84.6 \%$ of cases and communication between the social worker and GPs was rated as good in $46.2 \%$ of cases. When PCC directors were asked whether primary care professionals should play an active role in management of mental health problems $46.2 \%$ were neutral about the role of GPS and $53.8 \%$ were neutral about the role of primary care nurses. Finally, $69.3 \%$ of PCC directors agreed or totally agreed that social workers have an active role in management of mental health problems (Table 2).

In total there were $7087 \mathrm{GP}$ visits during the 42-month observation period (annual mean $=4.1$ visits per patient, 
Table $\mathbf{2}$ Organisation of the primary care centres

\begin{tabular}{ll}
\hline & Primary care centres N (\%) \\
\hline Social worker & \\
Shared & $7(53.8 \%)$ \\
Full time & $6(46.2 \%)$
\end{tabular}

Primary care physicians play an active role in managing patients' mental health

$\begin{array}{ll}\text { Neither agree nor disagree } & 6(46.2 \%) \\ \text { Agree } & 5(38.5 \%) \\ \text { Completely agree } & 2(15.4 \%)\end{array}$

Frequency of mental health care visits in primary care centres

$\begin{array}{ll}\text { Twice a month } & 4(30.8 \%) \\ \text { More than three times a month } & 9(69.2 \%)\end{array}$

Frequency of mental health training sessions in primary care centres

$\begin{array}{ll}\text { None } & 3(23.1 \%) \\ \text { Once a year or less } & 1(7.7 \%) \\ \text { Between } 4 \text { and } 6 \text { months } & 1(7.7 \%) \\ \text { Every } 2 \text { months } & 2(15.4 \%) \\ \text { Once a month } & 4(30.8 \%) \\ \text { Twice a month } & 1(7.7 \%) \\ \text { More than three times a month } & 1(7.7 \%)\end{array}$

How would you rate the communications between the primary care centre and the community mental health centre?

$\begin{array}{ll}\text { Neither good nor bad } & 1(7.7 \%) \\ \text { Good } & 6(46.2 \%) \\ \text { Very good } & 6(46.2 \%)\end{array}$

How would you rate the communications between primary care physicians and nurses?

$\begin{array}{ll}\text { Good } & 11(84.6 \%) \\ \text { Very good } & 2(15.4 \%)\end{array}$

Nurses play an active role in managing patients' mental health

$\begin{array}{ll}\text { Completely disagree } & 1(7.7 \%) \\ \text { Neither agree nor disagree } & 7(53.8 \%) \\ \text { Agree } & 2(15.4 \%) \\ \text { Completely agree } & 3(23.1 \%)\end{array}$

How do you rate the level of communication between primary care physicians and social workers?

$\begin{array}{ll}\text { Not applicable } & 1(7.7 \%) \\ \text { Neither good nor bad } & 3(23.1 \%) \\ \text { Good } & 6(46.2 \%) \\ \text { Very good } & 3(23.1 \%)\end{array}$

Social workers play an active role in managing patients' mental health

$\begin{array}{ll}\text { Not applicable } & 1(7.7 \%) \\ \text { Disagree } & 1(7.7 \%) \\ \text { Neither agree nor disagree } & 2(15.4 \%) \\ \text { Agree } & 4(30.8 \%) \\ \text { Completely agree } & 5(38.5 \%) \\ \text { Total } & 13(100 \%)\end{array}$

42-month mean $=14.35$ visits per patient, 42-month SD $($ Standard Deviation $)=12.44$, range $=0-75)$.

Results of the bivariate analysis are shown in Tables 3 and 4.The full multilevel, linear regression model explained $17.5 \%$ of the estimated variance in GP visits. The patient variables that were independently positively associated with number of GP visits were: female sex $(p<0.001)$; being married/living with partner $(p=0.005)$, being separated/divorced/widowed $(p=0.048)$; living in a socioeconomically deprived area $(p=0.002)$. The following patient variables were associated with fewer GP visits relative to diagnosis of schizoaffective disorder: diagnosis of schizophrenia $(p=0.005)$, persistent delusional disorders $(p=0.05)$, acute and transient psychotic disorders $(p=0.004)$ and schizotypal disorder, induced delusional disorder, other non-organic psychotic disorder or unspecified non-organic psychosis $(p=0.012)$. With regard to PCC variables, having a GP who took a more active approach to mental health issues was positively associated with number of GP visits. However, good or very good communication between the mental health team and primary care professionals was associated with fewer GP visits (Table 5).

\section{Discussion}

This study used multilevel linear regression to examine associations between number of GP visits and patient and organisational factors. Some patient variables - female sex, having been married or cohabiting at some point and a diagnosis of schizoaffective disorder - were positively associated with number of GP visits. Another important finding was that having a GP who took a more active approach to mental health issues was positively associated with number of GP visits, whereas the presence of good or very good care communication

Table 3 Bivariate analysis between dichotomous variables and number of contact with general practitioner

\begin{tabular}{llll}
\hline & Median & W Wilconxon & $P$ valor \\
\hline Area & & 17,262 & 0.001 \\
Urban & 12 & & \\
Rural & 7.5 & & \\
Mental health area & & & \\
North & 11 & & \\
Centre & 13 & & \\
Socioeconomic deprived area & & 0.1409 \\
Yes & 11 & & \\
No & 16 & & 0.0000 \\
Gender & 11 & 35,144 & \\
Male & 11 & & \\
Female & 17 & & \\
\hline
\end{tabular}


Table 4 Bivariate analysis between categorical variables and number of contact with general practitioner

\begin{tabular}{|c|c|c|c|}
\hline & Krukal-Wallis Chi cuadrado & d.f. & $P$ value \\
\hline Age (3 groups) & 1.12 & 2 & 0.572 \\
\hline Marital status & 12.29 & 2 & 0.002 \\
\hline Educational level & 2.35 & 3 & 0.504 \\
\hline Living arrangements & 6.21 & 4 & 0.184 \\
\hline Employment status & 2.97 & 5 & 0.705 \\
\hline Primary care centre & 40.93 & 16 & 0.000 \\
\hline ICD-10 clinical diagnosis & 10.35 & 4 & 0.035 \\
\hline Primary care physicians play an active role in managing patients' mental health & 11.95 & 2 & 0.003 \\
\hline Frequency of visits to primary health care centres to manage mental health & 1.19 & 1 & 0.276 \\
\hline Frequency of mental health training sessions in primary healthcare centres & 35.91 & 6 & 0.000 \\
\hline $\begin{array}{l}\text { How would you rate the communications between the primary care centre } \\
\text { and the community mental health centre? }\end{array}$ & 6.63 & 2 & 0.036 \\
\hline How would you rate the communications between primary care physicians and nurses? & 4.58 & 1 & 0.032 \\
\hline Nurses play an active role in managing patients' mental health & 7.85 & 3 & 0.005 \\
\hline How would you rate the communications between primary care physicians and social workers? & 6.90 & 3 & 0.075 \\
\hline Social workers play an active role in managing patients' mental health & 13.62 & 4 & 0.009 \\
\hline
\end{tabular}

between the PCC and community mental health professionals was negatively associated with number of GP visits.

The mean annual number of patient contacts with GP was 4.1, which is in line with other reports $[5,16,19]$. Our results show that in the area we studied the majority of patients were in contact with primary care professionals, only $3.2 \%$ had no contact with a GP during the observation period, which is even lower than in a study conducted in Norway, in which the percentage of patients who had no contacts with a GP was 17\% [19].

The multilevel linear regression showed that women made more visits to their GP, which is in line with other studies $[4,15,19]$. The analysis also showed that patients who were married or living with a partner had more contact with PPCs than singles, as in an earlier study [15] and this may have been because family support helped to ensure they received continuing care. However, we also found that patients who were separated, divorced or widowed also visited their GP more frequently than singles, in contrast to the aforementioned study [15]. Number of GP visits was also positively associated with a diagnosis of schizoaffective disorder. We have not found any other study that analysed the relationship between GP visits and form of psychotic disorder. Living in a socioeconomically deprive areas was positively associated with number of GP visits, which is consistent with a previous study [20]. This may be because in areas of socioeconomic deprivation the incidence of SRD is greater [21].

We found that GPs who took a more active approach to mental health issues were visited more frequently by patients, which implies a better medical follow-up of the patient. However communication between PCC and CMHCs was negatively associated with number of GP visits. This may be because good communication between the team resulted in community mental health professionals assuming some of the functions that would otherwise have been performed by the GP, such as monitoring physical health problems, and this could be because GPs feel unprepared and with low confidence in treating patients with severe mental health problems $[22,23]$, even if it is about their physical health problems. In the CMHU of the Regional Hospital in Malaga specialist mental health care has been coordinated with primary care for more than 20 years. This coordination means that once a week PCCs are visited by a specialist mental health professional who will deliver care to patients with less severe mental illness. In addition, mental health and primary care professionals hold joint meetings about patients. We found that mental health team visits to PCCs usually occurred 3 or more times a month and training visits took place once a month. In $92.4 \%$ of cases communication between the CMHU and GP was rated at as good or very good; in a similar study carried out in Catalonia cooperation between primary care and specialist services in mental health was considered satisfactory [24]. These results contrast with a report that French GPs thought there was a lack of communication between mental health services and primary care services [25]. The importance of collaboration between primary care and specialist mental health services has been shown in several studies. Good communication is associated with greater GP satisfaction with specialist services, 
Table 5 Multilevel linear regression of number of contact of patient with Schizophrenia and related disorders, $N=494$

\begin{tabular}{lll}
\hline & Coefficient & $P$ value \\
\hline Gender & & \\
Women & 1 & \\
Men & -5.783 & 0.000 \\
Area & & \\
Urban & 1 & \\
Rural & 3.496 & 0.0939 \\
Marital status & & \\
Single & 1 & \\
Married/Civil partnership/Cohabiting & 4.258 & 0.0051 \\
Separated/Divorced/Widowed & 3.518 & 0.0486 \\
ICD-10 clinical diagnosis & & \\
F25 & 1 & \\
F20 & -10.825 & 0.0051 \\
F22 & -5.299 & 0.0494 \\
F23 & -7.902 & 0.0035 \\
F21, F24, F28, F29 & -5.481 & 0.0124 \\
Socioeconomically deprived area & & \\
No & & \\
Yes & & \\
Primary care physicians play an active role & & \\
in managing patients' mental health & & \\
Neither agree nor disagree & & \\
Agree & & \\
Completely agree & & \\
How would you rate the communications & & \\
between the primary care centre and the & & \\
community mental health centre? & & \\
\hline
\end{tabular}

shorter referral times, shorter treatment duration, fewer appointments and lower treatment costs [26]. Although GPs feel responsible for management of physical or mental health in schizophrenia and are willing to work with mental health teams [10] and early interventions [27], they have yet to embrace it. A robust system of collaboration between levels of care would be necessary to achieve this [28-30].

\section{Strengths and limitations}

A strength of this study is that we analysed a large, homogeneous sample of patients with a diagnosis of SRD living in the community and have thus provided an unbiased picture of GP visits by this population. We also want to point out that we have used multilevel linear regression with two levels, patient and PPC.

As to limitations, this was a cross-sectional study so we cannot infer causality, only association. In addition diagnoses were not based on structured diagnostic interviews, but they were clinical diagnoses made by the patients' long-term psychiatrists and updated in the RESMA database. The data were obtained from databases that are routinely filled in clinical practice, so we cannot their reliability. Finally, it would have been interesting to have data on a matched control population.

\section{Conclusions}

Our results reveals that the number of GP visits made by patients with SRD is affected by organisational factors, such as the GP's approach to mental health issues, as well as patients factors.

Medical follow-up of the physical illness is crucial in patients with SRD, and primary care services are central in it. More studies are needed in this field; in this way we improve awareness of the need for GPs' involvement in managing the physical health of patients with SRD.

\section{Additional file}

Additional file $\mathbf{1}$ Table S1. Study variables. (DOCX $15 \mathrm{~kb}$ )

\section{Acknowledgements}

The authors acknowledge the Primary Care District of Malaga, particularly Maximiliano Vilaseca, Francisco Javier Navarro for their support. We are also grateful to the directors and general practitioners at all the general practices that participated in this study. Finally we thank Santiago Galan for his assistance with information collection.

\section{Funding}

This project was funded by Consejería de Economía, Innovación,Ciencia y Empleo, Junta de Andalucía (Award Number: P10-CTS-5862, CTS-945)and by Fundación Progreso y Salud (Award Number: PI-0193/2014).

\section{Availability of data and materials}

The data that support the findings of this study are available from Berta Moreno Küstner but restrictions apply to the availability of these data, which were used under license for the current study, and so are not publicly available. Data are however available from the authors upon reasonable request and with permission of Berta Moreno Küstner.

\section{Authors' contributions}

MCA, CMP, FMC and BMK made substantial contributions to conception and design, acquisition of data, and analysis and interpretation of data. MCA, CMP and BMK were involved in drafting the manuscript or revising it criticallyfor important intellectual content. All authors gave final approval of the version of to be published and agreed to be accountable for all aspects of the work in ensuring that questions related to the accuracy or integrity of any part of thework were appropriately investigated and resolved.

\section{Ethics approval and consent to participate}

The present study was approved by the Health Research Ethics Committee of the Health District of Malaga.

\section{Consent for publication}

Data confidentiality was guaranteed under Organic Law 15/1999 on the Protection of Personal Data. 


\section{Competing interests}

The authors declare that they have no competing interests.

\section{Publisher's Note}

Springer Nature remains neutral with regard to jurisdictional claims in published maps and institutional affiliations.

\section{Author details}

'Departament of Personality, Assessment and Psychological Treatment, University of Malaga, Campus Teatinos, Malaga, Spain. ${ }^{2}$ Andalusian Group of Psychosocial Research (GAP), Malaga, Spain. ${ }^{3}$ Andalusian Health Service, North East Granada Sanitary District, Clinical Management Unit at Marquesado, Carretera los Pozos, Alquife, Granada, Spain. ${ }^{4}$ Clinical Management Unit of Mental Health of the Regional Hospital of Malaga, Andalusian Health Service, Paseo Limonar, Malaga, Spain. ${ }^{5}$ Biomedical Research Institute of Malaga (IBIMA), Plaza del Hospital, Malaga, Spain. ${ }^{6}$ Alameda-Perchel basic primary care team, Health District Malaga-Guadalhorce, Andalusian Health Service, Avenida Manuel Agustín Heredia, Malaga, Spain. ${ }^{7}$ Departament of Personality, Assessment and Psychological Treatment, University of Malaga, Campus Teatinos, Malaga, Spain.

Received: 15 May 2018 Accepted: 13 November 2018

Published online: 28 November 2018

\section{References}

1. Temmingh HS, Oosthuizen PP. Pathways to care and treatment delays in first and multi episode psychosis. Soc Psychiatry Psychiatr Epidemiol. 2008;43:727-35.

2. Smith DJ, Langan J, McLean G, Guthrie B, Mercer SW. Schizophrenia is associated with excess multiple physical-health comorbidities but low levels of recorded cardiovascular disease in primary care: cross-sectional study. BMJ Open. 2013;3(4).

3. De Hert M, Dekker JM, Wood D, Kahl KG, Holt RI, Möller HJ. Physical illness in patients with severe mental disorders. I. Prevalence, impact of medications and disparities in health care. World Psychiatry. 2011;10(1):52-77.

4. Chwastiak LA, Rosenheck RA, Kazis LE. Utilization of Primary Care by Veterans with Psychiatric Illness in the National Department of Veterans Affairs Health Care System. J Gen Intern Med. 2008;23(11):1835-40.

5. Castillo-Sánchez M, Fàbregas-Escurriola MD, Bergè-Baquero D, Foguet-Boreu Q, Fernández-San Martín MI, Goday-Arno A. Schizophrenia, antipsychotic drugs and cardiovascular risk: Descriptive study in primary care. Eur Psychiatry. 2015;30:535-41.

6. Gur S, Weizman S, Stubbs B, Matalon A, Meyerovitch J, Hermesh H, et al. Mortality, morbidity and medical resources utilization of patients with schizophrenia: A case-control community-based study. Psychiatry Res. 2018;260:177-81.

7. Simon AE, Lester H, Tait L, Stip E, Roy P, Conrad G, et al. The International Study on General Practitioners and Early Psychosis (IGPS). Schizophr Res. 2009:108(1-3):182-90.

8. Hendrie HC, Hay D, Lane KA, Gao S, Purnell C, Munger S, et al. Comorbidity Profile and Health Care Utilization in Elderly Patients with Serious Mental IIInesses. Am J Geriatr Psychiatry. 2013;21(12):1267-76.

9. Bresee LC, Majumbar SC, Patten SB, Jeffrey AJ. Utilization of General and Specialized Cardiac Care by People with Schizophrenia. Psychiatr Serv. 2012;63:3

10. Oud MJT, Meyboom-de Jong B. Somatic diseases in patients with schizophrenia in general practice: their prevalence and health care. BMC Fam Pract. 2009;10:32.

11. Woodhead C, Ashworth M, Broadbent M, Callard F, Hotopf M, Schofield P, et al. Cardiovascular disease treatment among patients with severe mental illness: a data linkage study between primary and secondary care. Br J Gen Pract. 2016;66(647):e374-81.

12. Crompton D, Groves A, McGrath J. What can we do to reduce the burden of avoidable deaths in those with serious mental illness? Soc Psychiatry Psychiatr Epidemiol. 2010;19(1):4-7.

13. Roberts L, Roalfe A, Wilson S, Lester H. Physical health care of patients with schizophrenia in primary care: a comparative study. J Fam Pract. 2007;24:34-40.

14. Osborn DPJ, Baio G, Walters K, Petersen I, Limburg H, Raine R, et al. Inequalities in the provision of cardiovascular screening to people with severe mental illnesses in primary care Cohort study in the United
Kingdom THIN Primary Care Database 2000-2007. Schizophr Res. 2011:129:104-10.

15. Copeland LA, Zeber JE, Wang CP, Parchman ML, Lawrence VA, Valenstein $\mathrm{M}$, et al. Patterns of primary care and mortality among patients with schizophrenia or diabetes: a cluster analysis approach to the retrospective study of healthcare utilization. BMC Health Serv Res. 2009;9:127.

16. Reilly S, Planner C, Hann M, Reeves D, Nazareth I, Lester H. The Role of Primary Care in Service Provision for People with Severe Mental IIIness in the United Kingdom. PLoS One. 2012;7(5):e36468.

17. Moreno-Küstner B, Mayoral F, Pérez O, Angona P, Requena J, GarcíaHerrera JM, et al. The Malaga schizophrenia case-register (RESMA): overview of methodology and patient cohort. Int J Soc Psychiatry. 2009;55(1):5-15

18. Moreno-Küstner B, Mayoral F, Navas-Campaña D, García-Herrera JM, Angona P, Martín C, et al. Prevalence of schizophrenia and related disorders in Malaga (Spain): results using multiple clinical databases. Epidemiol Psychiatr Sci. 2016;25:38-48.

19. Hetlevik $\varnothing$, Solheim M, Gjesdal S. Use of GP services by patients with schizophrenia:a national cross-sectional register-based study. BMC Health Serv Res. 2015;15:66.

20. Drukker M, Driessen G, Krabbendam L, van Os J. The wider social environment and mental health service use. Acta Psychiatr Scand 2004; 110:119-129.

21. Castillejos M, Martín-Pérez C, Moreno-Küstner B. A systematic review and metaanalysis of the incidence of psychotic disorders: The distribution of rates and the influence of gender, urbanicity, immigration and socio-economic level. Psychol Med. 2018. https://doi.org/10.1017/S0033291718000235.

22. Bagayogo IP, Turcios-Wiswe K, Kanako T, Peccoralo L, Katz CL. Providing Mental Health Services in the Primary Care Setting: the Experiences and Perceptions of General Practitioners at a New York City Clinic. Psychiatr Q. 2018:1-12.

23. Caplan S, Little TV, Garces-King J. Stigma About Mental IIness Among Multidisciplinary Health Care Providers in the Dominican Republic. Int Perspect Psychol. 2016;5(3):192-206.

24. Luciano JV, Fernández A, Serrano-Blanco A, Pinto-Maeza A, Palao DJ, Mercader M, et al. Cooperación entre atención primaria y servicios de salud mental. Aten Primaria. 2009:41(3):131-40.

25. Verdoux H, Cougnard A, Grolleau S, Besson R, Delcroix F. How do general practitioners manage subjects with early schizophrenia and collaborate with mental health professionals? A postal survey in South-Western France. Soc Psychiatry Psychiatr Epidemiol. 2005;40:892-8.

26. van Orden M, Hoffman T, Haffmans J, Spinhoven P, Hoencamp E. Collaborative mental health care versus care as asual in primary care setting: a randomized controlled trial. Psychiatr Serv. 2009;60(1):74-9.

27. Takamura M, Hagi N, Yokoyama K. Motivation of Primary Care Physicians for Participating in Early Intervention for Psychosis in Japan. Tohoku J Exp Med. 2011;225(1):43-9.

28. Heald A, Montejo AL, Millar H, De Hert M, McCrae J, Correll CU. Management of physical health in patients with schizophrenia: practical recommendations. Eur Psychiatry. 2010;25:\$41-5.

29. Jones R, Major B, Fear C. Schizophrenia in a Primary Care Setting. Curr Psychiatry Rep. 2015;17:84.

30. Ritchie S, Muldoon L. Cardiovascular preventive care for patients with serious mental illness. Can Fam Physician. 2017;63(11):e483-7.

Ready to submit your research? Choose BMC and benefit from:

- fast, convenient online submission

- thorough peer review by experienced researchers in your field

- rapid publication on acceptance

- support for research data, including large and complex data types

- gold Open Access which fosters wider collaboration and increased citations

- maximum visibility for your research: over $100 \mathrm{M}$ website views per year

At $\mathrm{BMC}$, research is always in progress.

Learn more biomedcentral.com/submissions 